\title{
(2) OPEN ACCESS \\ Developing drowning prevention strategies for rivers through the use of a modified Delphi process
}

\author{
Amy E Peden (1) ,1,2 Richard C Franklin (1) 1,2 Peter A Leggat ${ }^{2,3}$
}

- Additional material is published online only. To view please visit the journal online (http://dx.doi.org/10.1136/ injuryprev-2019-043156).

${ }^{1}$ Royal Life Saving Society Australia, Broadway, New South Wales, Australia

${ }^{2}$ College of Public Health, Medical and Veterinary Sciences, James Cook University, Townsville, Queensland, Australia

${ }^{3}$ School of Medicine, College of Medicine, Nursing and Health Sciences, National University of Ireland, Galway, Ireland

\section{Correspondence to} Amy E Peden, Royal Life Saving Society - Australia, Broadway, New South Wales 2007, Australia; apeden@rlssa.org.au

Received 17 January 2019 Revised 13 March 2019 Accepted 14 March 2019 Published Online First 30 March 2019

\author{
ABSTRACT \\ Introduction Internationally, rivers are a leading \\ drowning location, yet little evidence exists evaluating \\ river drowning prevention strategies. This study aims to \\ use expert opinion to identify strategies more likely to be \\ effective.
}

Methods Using a modified Delphi process, a virtual panel of 30 experts from 12 countries considered, grouped and prioritised strategies for river drowning prevention. Proposed strategies were assessed against known evidence and suitability in high-income countries (HICs) as well as low-income and middle-income countries (LMICs) using expert opinion. The final phase consolidated a list of strategies whose effectiveness was assessed against 10 evidence-based river drowning scenarios.

Results An initial list of 424 prevention strategies was refined to 22 . After being assessed against the 10 scenarios, a final list of 13 strategies was derived. Strategies addressed alcohol consumption around rivers, flood mitigation, improving child supervision, learning to swim, increased lifejacket wear and achieving community-wide resuscitation skills.

Discussion While all 13 strategies were assessed as being effective in both LMICs and HICs by at least $60 \%$ of the respondents, further work is required to define river drowning at a country level and therefore allow for effective solutions to be developed, particularly in LMICs. No strategy will be effective in isolation and must be implemented alongside policy and behaviour change, public awareness and education. Evaluation should be incorporated as part of any future implementation of strategies.

Conclusion This Delphi process identified 13 drowning prevention strategies for rivers. Further research is required to validate the efficacy of these findings through implementation and evaluation.

\section{INTRODUCTION}

Identifying effective strategies for preventing injuries is challenging. ${ }^{1}{ }^{2}$ While effective strategies are available, further work is required to develop the supporting evidence, especially for the issue of drowning and drowning within low-income and middle-income countries (LMICs). ${ }^{3}$ Evidence informing the prioritisation of strategies more likely to be effective provides a useful starting point for resource allocation for implementation and subsequent evaluation.

The WHO estimates 360000 deaths from drowning annually. ${ }^{4}$ This figure is likely to be substantially higher, with a study from Australia showing the methodologies used by the WHO under-report unintentional fatal drowning by $40 \%{ }^{5}$ River drowning is a global problem, ${ }^{6-10}$ and therefore any prevention strategies implemented must consider the determinants of health ${ }^{11}$ and specific country contexts. In Australia, rivers are the leading location for drowning, ${ }^{12}$ with risk factors increasingly identified. ${ }^{12-14}$

Preventing drowning is challenging as it requires evidence-based changes in policy, behaviour, culture and environment. ${ }^{15-17}$ Prevention strategies across the drowning timeline (prepare, prevent, react and mitigate) are required. ${ }^{18}$ The hierarchy of control is a six-domain pyramid that provides a framework for thinking about the effectiveness of a prevention strategy. Strategies range in effectiveness across the six levels from elimination of the hazard (most effective), substitution, engineering, administrative controls, behaviour change and personal protective equipment (PPE). ${ }^{19}$ Strategies that are higher on the hierarchy of control, ${ }^{19}$ although often more difficult to implement, are more likely to be effective. ${ }^{20}$

Due to the significant burden of rivers in global drowning statistics, and little implementation and evaluation of river drowning prevention strategies, ${ }^{21}$ this study aimed to use expert opinion to identify strategies more likely to be effective in preventing river drowning.

\section{METHODS}

This study used a modified Delphi process to develop, refine and rank a range of proposed strategies for the prevention of unintentional drowning in rivers.

\section{Study design}

A conventional Delphi process is a long-range, qualitative forecasting technique ${ }^{22}$ based on achieving consensus among participants through optimal convergence of opinions. ${ }^{23}$ A typical Delphi uses a series of phases where information is fed back to panel members using questionnaires.

A Delphi process has previously been used to develop international guidelines to reduce recreational open water drowning deaths. ${ }^{24} 25$ The current study invited river drowning prevention researchers and practitioners from around the world to identify strategies more likely to be effective in preventing river drowning, through a series of surveys using SurveyGizmo. ${ }^{26}$ This study modified a Delphi process in that participants assessed the effectiveness as well as the relevance of strategies through the use of surveys and evidence-based scenarios. The study methodology is outlined below. 
Table 1 Categories of river drowning prevention strategies proposed by Delphi participants at phase $1(n=11)$

\begin{tabular}{|c|c|c|}
\hline Category & Strategies (n) & Example strategy \\
\hline Life jackets & 9 & Lifejacket wear for children. \\
\hline Personal behaviours & 17 & $\begin{array}{l}\text { Do not engage in water recreation in a } \\
\text { river alone. }\end{array}$ \\
\hline Knowledge & 10 & $\begin{array}{l}\text { Strategies to survive cold water } \\
\text { immersion. }\end{array}$ \\
\hline $\begin{array}{l}\text { Public awareness and } \\
\text { advocacy }\end{array}$ & 12 & $\begin{array}{l}\text { Raise awareness of the dangers of } \\
\text { submerged obstacles. }\end{array}$ \\
\hline $\begin{array}{l}\text { Cardiopulmonary } \\
\text { resuscitation }(C P R) \text { and } \\
\text { rescue }\end{array}$ & 7 & $\begin{array}{l}\text { Training for all boat personnel in CPR, } \\
\text { calling for rescue, and search and } \\
\text { rescue. }\end{array}$ \\
\hline Personal skills & 9 & $\begin{array}{l}\text { Teach self-rescue skills to enable } \\
\text { unaided movement to water's edge. }\end{array}$ \\
\hline Signage & 13 & $\begin{array}{l}\text { Highly visible signs warning of } \\
\text { local hazards at popular swimming } \\
\text { destinations. }\end{array}$ \\
\hline Engineering & 19 & $\begin{array}{l}\text { Safe and accessible infrastructure, such } \\
\text { as bridges, for crossing rivers. }\end{array}$ \\
\hline Flooding & 18 & $\begin{array}{l}\text { Establish effective early warning } \\
\text { systems for notifying at-risk citizens } \\
\text { when rivers are flooded. }\end{array}$ \\
\hline Alcohol & 11 & $\begin{array}{l}\text { Restriction of alcohol usage around hire } \\
\text { and drive vessels, such as houseboats } \\
\text { and party boats. }\end{array}$ \\
\hline Other & 14 & $\begin{array}{l}\text { Include river drowning prevention in } \\
\text { national and local water safety plans. }\end{array}$ \\
\hline Total & 139 & \\
\hline
\end{tabular}

\section{Participant selection}

Participants $(n=39)$ were identified by being active in drowning prevention research (ie, published in the last 5 years) and practice (eg, working in national parks or in disaster consultancy). The initial list of potential participants was identified through a systematic literature review, ${ }^{21}$ and additional practitioners and researchers were identified using purposive (ie, those known by the authors to be active in the field of river drowning prevention via publications, presentations and work practices) and snowballing (ie, if invited participants were unable or unwilling to participate, they suggested another similar person) sampling techniques. ${ }^{27}$ All prospective participants were contacted via email and sent the information sheet. Thirty (76.9\%) agreed to participate.

Phase 1: brainstorming prevention strategies

Using free-text responses, participants listed all strategies they thought would prevent river drowning. Participants were provided space to list 40 strategies. Two examples were provided, lifejackets and learn to swim (example strategies could be reused by respondents if deemed suitable). Responses were thematically coded into 11 categories by authors AEP and RCF using an inductive method ${ }^{28}$ (table 1). Duplicates were deleted and strategies similar in wording and intent were merged. The consolidated list was then compared with prevention strategies identified through the previously conducted systematic literature review $^{21}$ to ensure that any river drowning prevention strategies with supporting evidence, be it evaluated or proposed via expert opinion, were adequately addressed by the participants' suggestions. All nine proposed prevention strategies, as identified in the literature review, were sufficiently covered by the participants' suggestions.
Phase 2: prevention strategies ranked for effectiveness

The consolidated list was presented in categories. Respondents were asked to rank strategy's effectiveness on a 4-point scale ('very effective', 'effective', 'neutral' and 'not effective') with a 'don't know' option. Respondents could add strategies that were not previously included.

Phase 3: evaluation of proposed strategies' effectiveness in HICs and LMICs and awareness of the levels of supporting evidence Consistent with previous drowning-related Delphi processes, ${ }^{24} 25$ strategies with $60 \%$ agreement or more, and newly proposed strategies $(n=3)$, were carried through to phase 3 . New strategies were assessed against the same criteria from phase 2. All strategies (both new and existing) were assessed against their likelihood of effectiveness in countries of different income levels ('high income countries' [HICs], 'LMICs', 'both HICs and LMICs', 'neither' or 'don't know'). The specific question asked was 'In which of the following country income level categories would the following strategies be effective?' All strategies were also assessed against their known evidence on a scale of 'no evidence - I would remove', 'no evidence - I would keep', 'I am aware of evidence which supports this', 'I am aware of evidence which does not support this', 'I am unaware of any evidence - I would remove', and 'I am unaware of any evidence - I would keep'. Respondents did not have to provide examples of this evidence.

\section{Phase 4: alignment and prioritisation of strategies against river drowning scenarios}

At phase 4, respondents read 10 river drowning scenarios. These scenarios were based on an amalgam of common river drowning incidents in Australia. ${ }^{12}$ Scenarios accounted for $63.8 \%$ of river drowning deaths in Australia (table 2). Scenarios can be found in online supplementary table S1.

For each scenario, respondents identified the top 5 strategies they believed would be most effective in preventing a future similar drowning. Strategies were drawn from a consolidated list of strategies merged by authors AEP and RCF. Respondents could also list an 'other' strategy, if they felt the available strategies were not appropriate. Each 'other' strategy suggested for each scenario was evaluated by authors AEP and RCF and recoded into existing strategies where appropriate. Where $60 \%$ or more of the respondents aligned a strategy to a scenario, this strategy was retained. The final list of strategies was coded to the hierarchy of control by authors RCF and AEP.

\section{RESULTS}

Thirty participants $(70.0 \%$ male $[\mathrm{n}=21]$; $23.3 \%$ LMICs $[\mathrm{n}=7])$ made up the participant panel. Countries represented included USA $(n=7 ; 23.3 \%)$, Australia $(n=6 ; 20.0 \%)$, England $(n=3$; 10.0\%), Canada, The Netherlands, Philippines, South Africa $(\mathrm{n}=2 ; 6.7 \%$, respectively), Uganda, Brazil, Bangladesh, Switzerland and Ireland ( $n=1 ; 3.3 \%$, respectively). Eleven participants $(36.7 \%)$ are practitioners, $7(23.3 \%)$ are researchers and 12 $(40.0 \%)$ are both.

Phase 1 (response rate 100.0\%) yielded 424 strategies (figure 1), with the mean number of responses being 15 strategies (range 6-35). Thirty-two duplicates were removed. The remaining 392 were merged into 139 strategies across 11 categories. This list then proceeded to phase 2 .

After being ranked based on their likely effectiveness at phase 2 (response rate $100.0 \%$ ), the 32 strategies that achieved less than $50 \%$ agreement were defined as requiring more evidence 
Table 2 Epidemiological profile of unintentional river drowning deaths in Australia on which river drowning scenarios assessed by Delphi participants at phase 4 were based

\begin{tabular}{lrc}
\hline River drowning scenario & $\mathbf{n}$ & $\%$ \\
\hline River drowning in remote and very remote areas & 131 & 17.0 \\
Males 55+ and pre-existing medical conditions & 118 & 15.3 \\
Driving into floodwaters & 71 & 9.2 \\
Females and falls into rivers & 41 & 5.3 \\
Males 55-74 boating incidents & 26 & 3.4 \\
Children 0-4 and falls & 24 & 3.1 \\
Males 18-34 and swimming and recreating with alcohol & 22 & 2.9 \\
Fishing from edge & 20 & 2.6 \\
Males 25-54 years boating and alcohol & 20 & 2.6 \\
Males 15-24 who jump in & 18 & 2.3 \\
Total & 491 & 63.8 \\
\hline
\end{tabular}

Note: Data are derived from a total population analysis of unintentional fatal river drowning in Australia between 2002 and 2012, drawn primarily from the National Coronial Information System. These data have been published previously (see ref12).

and were removed (online supplementary table S2). Strategies with the lowest ranking for effectiveness can be found in online supplementary table S2. Strategies that showed promise (ie, scoring between $50 \%$ and 59\% effectiveness [n=29]) were also removed (online supplementary table S3). Fourteen newly suggested duplicates were also removed or thematically combined with similar strategies.

Of the 64 strategies assessed at phase 3 (response rate 93.3\%), $74.6 \%$ were assessed as being effective in both LMICs and HICs by $60 \%$ or more of the respondents. The strategy assessed as being most likely to be effective in both LMICs and HICs were 'School based river safety education', assessed by $92.9 \%$ of the respondents as being effective (100.0\% of LMIC respondents and $86.4 \%$ of HIC respondents). The strategies deemed least likely to be effective in both contexts were 'Lifejacket loaner programs near popular river access points' (overall effectiveness in both contexts $32.1 \%$; effectiveness in HICs $50.0 \%$; effectiveness in LMICs 7.1\%) and 'Wearing a lifejacket when rivers flows are fast and water is cold' (overall effectiveness in both contexts 42.9\%; effectiveness in HICs 32.1\%; effectiveness in LMICs 3.6\%).

When examining the results based on the country context of the Delphi participants, $100 \%$ of participants from LMICs assessed 'Providing safe places away from rivers for pre-school aged children (eg, daycare/crèche)' as being effective in reducing river drowning in LMIC contexts, while 68\% of HIC participants assessed it as being effective in HIC contexts. By contrast, a strategy such as 'If participating in known hazardous events (eg, river rafting/white water boating) have a local guide present' was assessed as being effective in HICs by $82 \%$ of participants from HICs, while only 50\% of LMIC participants assessed the strategy as being effective in LMICs.

When ranking the levels of evidence, $16.4 \%$ of strategies were reported by $60 \%$ of the respondents or more as having evidence they were aware of which supported the strategy as being effective in reducing river drowning. The strategy with the strongest supportive evidence was 'Provide safe places away from rivers for pre-school aged children (eg, day-care/crèche)' (85.7\% of the respondents being aware of evidence that supported the strategy). 'Risk assessment and management of areas where people jump in' was the strategy with the lowest level (10.7\%).

The effectiveness of three newly introduced strategies were assessed, with one (Use of a rating system for all signage that is an assessment at specific locations') removed as it was assessed as being effective or very effective in preventing river drowning by only $28.6 \%$ of the respondents (online supplementary table S2). The remaining two, 'Apply a common risk rating system for rivers where people frequent' and 'Urban design for runoff retention to reduce high river flow and flooding', scored highly enough to be carried through, resulting in a total of 66 strategies.

Prior to phase 4 (response rate 93.3\%), authors AEP and RCF consolidated the strategies, refining 66 strategies to 22 (which included an 'other - please specify' option) (see online supplementary table S4 for the numbered list of original strategies and table 3 for how these were merged).

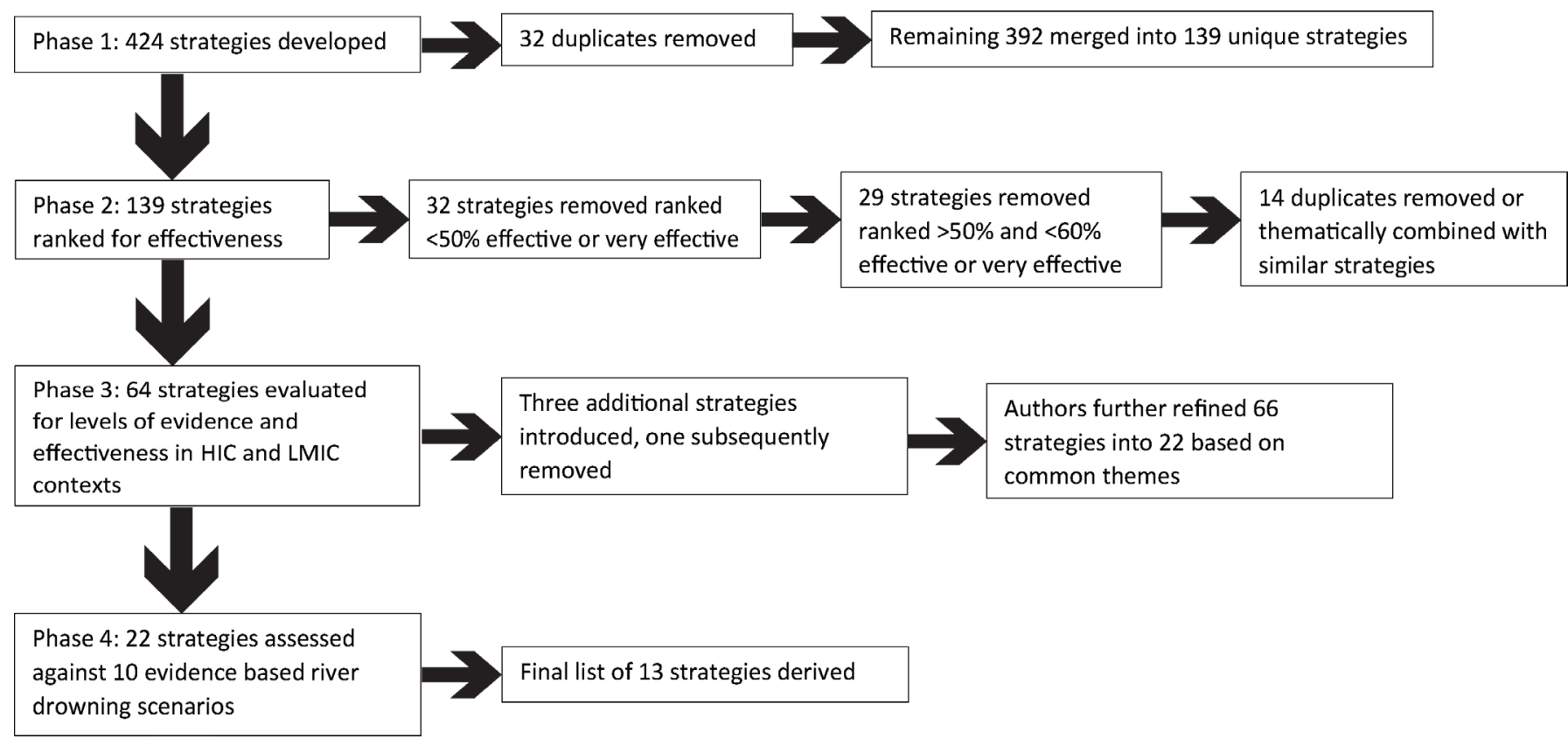

Figure 1 Flow chart of the modified Delphi process. HIC, high-income country; LMIC, low-income and middle-income country. 
Table 3 Merging of similar or duplicate strategies for use at phase 4 of the Delphi

\begin{tabular}{ll}
\hline Revised river drowning prevention strategy & $\begin{array}{l}\text { Original strategies } \\
\text { combined (see online } \\
\text { supplementary Table S4) }\end{array}$ \\
\hline Apply a risk rating system & 1 \\
\hline Wear a life jacket & $2-7$ \\
\hline Avoid open water at night & 8 \\
\hline Signage & $9-12$ \\
\hline $\begin{array}{l}\text { Swim/recreate/wash/bathe only in designated safe } \\
\text { places }\end{array}$ & $13-17$ \\
\hline Caregivers maintaining active supervision & 18 \\
\hline Do not engage in water recreation alone & 19 \\
\hline Barriers between child play areas and rivers & $20-21$ \\
\hline $\begin{array}{l}\text { Strategies to survive cold water immersion } \\
\text { River safety education including recognition and }\end{array}$ & 22 \\
awareness of hazards & $23-35$ \\
\hline Community-wide rescue and resuscitation skills & $36-37$ \\
\hline Raise awareness of the risks of drowning from alcohol & $38-42$ \\
\hline Public rescue equipment available & 43 \\
\hline Learn to swim with a focus on survival swimming skills & $44-45$ \\
\hline Build safe and accessible infrastructure such as bridges & 46 \\
\hline Designing the urban landscape to improve safety & $47-51$ \\
\hline $\begin{array}{l}\text { Close flooded roads and/or use physical barriers (such } \\
\text { as booms) }\end{array}$ & $52-54$ \\
\hline Prohibiting/Restricting alcohol use & $55-58$ \\
\hline Establish effective early warning systems & $59-61$ \\
\hline $\begin{array}{l}\text { Community risk mapping and assessment to formulate } \\
\text { targeted prevention programme }\end{array}$ & $62-65$ \\
\hline $\begin{array}{l}\text { Sustainable land use to prevent flooding } \\
\text { Other (please specify) }\end{array}$ & 66 \\
\hline & - \\
\hline
\end{tabular}

Participants were then asked to align the proposed river drowning prevention strategies to the river drowning scenarios they felt the strategy would be most effective at preventing. The strategies of 'Wear a lifejacket' (110.7\% for scenario 3$)$ and 'Caregivers maintaining active supervision' (107.1\% for scenario 4) were the strategies with the highest support from respondents (scoring over 100\% when 'other' similarly worded strategies were recoded). The most commonly recommended strategy was 'River safety education including recognition and awareness of hazards' (recommended by $60 \%$ or more of the respondents in 7 of the 10 scenarios) (table 4 ).

A final list of 13 strategies was derived. Strategies address alcohol $(n=2)$, flood-related measures $(n=2)$ and child drowning prevention (barriers and supervision). Strategies such as 'Prohibiting/restricting alcohol use' and 'Don't engage in water recreation alone' are the highest on the hierarchy of control, defined as elimination-level strategies (table 5).

\section{DISCUSSION}

River drowning accounts for a significant proportion of global drowning burden. ${ }^{12} 29$ This modified Delphi process addresses a gap in evaluated prevention strategies in the literature, ${ }^{21}$ using researchers and practitioners to identify river drowning strategies.

An initial list of 424 strategies was refined to 13 which would address $63.8 \%$ of Australian fatal river drowning. Strategies target the use of barriers, school-based river safety education, alcohol consumption, flooding, the establishment of safe places, infrastructure, discouraging water recreation alone, use/wear of life jackets, learning to swim, community-wide rescue and resuscitation skills, improving child supervision, and designing the urban landscape. Key issues identified throughout the Delphi process are now discussed.

\section{Hierarchy of control}

Although lower order strategies such as signage and administrative strategies were more likely to be recommended by coroners when investigating the prevention of river drowning deaths in Australia, ${ }^{30}$ strategies which are higher on the hierarchy of control are more likely to be effective. ${ }^{19}{ }^{20}$ The final list of 13 river drowning prevention strategies spanned the hierarchy, ranging from higher order strategies focused on elimination such as 'Prohibiting/restricting alcohol use' to lower order strategies such as PPE, 'Wear a lifejacket'. Higher order strategies, based on a sound evidence with adequate resourcing and timeframes, implemented in a supportive environment with policy and behaviour change, should be prioritised. ${ }^{15}$

\section{Lifejackets}

The use and wear of lifejackets was one of the most commonly proposed strategies, also recommended by the WHO, ${ }^{4}$ with 29 individual strategies mentioning lifejackets at phase 1 . For the $14 \%$ of boating and watercraft-related river drowning deaths in Australia, evidence supports wearing lifejackets ${ }^{31} 32$ and have also been found to be effective for those recreating in water. ${ }^{33}$ However, in order to be effective, a supportive environment must exist whereby policy (and enforcement) ${ }^{15} 34$ provides a mechanism for increasing the carriage and wear of lifejackets.

A barrier to use in LMICs, however, is access to low-cost lifejackets. ${ }^{4}$ Despite $57 \%$ of respondents to the Delphi process stating that the river drowning strategy of 'Wear a lifejacket' would be effective in both HICs and LMICs, there is a dearth of research from rivers and LMICs on the issue of lifejackets. ${ }^{35}$ Lifejackets must be seen as an active prevention strategy (to be worn whenever boating), rather than a reactive one (putting a lifejacket on once the boat has capsized). ${ }^{36}$ Although beyond the scope of this Delphi, the authors note that any river drowning prevention strategy focused on lifejackets must address the personal, social and environmental factors underpinning lifejacket wear behaviour, ${ }^{35}$ as well as suitability and availability of lifejackets in the particular country where they are proposed to be used.

\section{River safety education}

Education has long been regarded as a key facet of comprehensive approaches to the prevention of injury, ${ }^{37} 38$ including drowning. ${ }^{21} 363940$ This aligns with the Delphi findings with 'River safety education including recognition and awareness of hazards', the only drowning prevention strategy that appeared in the top 5 for every river drowning scenario. Education must be guided by good evidence, ${ }^{36}$ which may be a challenge given the lack of research on river drowning. ${ }^{21}$ Education must also form part of a broader strategy (commonly recognised as being enforcement and engineering) in order to be successful. ${ }^{41}$

\section{Rescue and resuscitation skills}

The strategy of 'Community wide rescue and resuscitation skills' was recommended, in particular, for the river drowning scenario associated with aquatic recreation in isolated areas without timely access to medical assistance. This is pertinent, given $17 \%$ of fatal unintentional river drowning in Australia occurs in remote and very remote locations, ${ }^{12}$ likely to be some distance from timely 
Table 4 Top 5 strategies recommended for each river drowning scenario at phase 4 of the Delphi

\begin{tabular}{|c|c|c|c|c|c|c|c|c|c|c|c|}
\hline Scenario & $\begin{array}{l}\text { Summary of } \\
\text { scenario }\end{array}$ & Strategy 1 & $\%$ & Strategy 2 & $\%$ & Strategy 3 & $\%$ & Strategy 4 & $\%$ & Strategy 5 & $\%$ \\
\hline 1 & $\begin{array}{l}60 \text {-year-old } \\
\text { male, alcohol } \\
\text { consumption, } \\
\text { driving into } \\
\text { floodwaters at } \\
\text { night. }\end{array}$ & $\begin{array}{l}\text { Close flooded roads } \\
\text { and/or use physical } \\
\text { barriers (such as } \\
\text { booms). }\end{array}$ & 96.4 & $\begin{array}{l}\text { Build safe and } \\
\text { accessible } \\
\text { infrastructure such } \\
\text { as bridges. }\end{array}$ & 75.0 & $\begin{array}{l}\text { River safety } \\
\text { education including } \\
\text { recognition and } \\
\text { awareness of } \\
\text { hazards. }\end{array}$ & 53.6 & $\begin{array}{l}\text { Prohibiting/ } \\
\text { Restricting alcohol } \\
\text { use. }\end{array}$ & 42.9 & $\begin{array}{l}\text { Establish effective } \\
\text { early warning systems. } \\
\text { Raise awareness of } \\
\text { the risks of drowning } \\
\text { from alcohol. }\end{array}$ & $\begin{array}{l}39.3 \\
39.3\end{array}$ \\
\hline 2 & $\begin{array}{l}\text { 24-year-old } \\
\text { male, alcohol } \\
\text { consumption, } \\
\text { poor swimmer, } \\
\text { strong current. }\end{array}$ & $\begin{array}{l}\text { River safety } \\
\text { education including } \\
\text { recognition and } \\
\text { awareness of } \\
\text { hazards. }\end{array}$ & 89.3 & $\begin{array}{l}\text { Raise awareness } \\
\text { of the risks of } \\
\text { drowning from } \\
\text { alcohol. }\end{array}$ & 82.1 & $\begin{array}{l}\text { Swim/recreate/ } \\
\text { wash/bathe only } \\
\text { in designated safe } \\
\text { places. }\end{array}$ & 78.6 & $\begin{array}{l}\text { Prohibiting/ } \\
\text { Restricting alcohol } \\
\text { use. }\end{array}$ & 57.1 & $\begin{array}{l}\text { Public rescue } \\
\text { equipment available. }\end{array}$ & 57.1 \\
\hline 3 & $\begin{array}{l}\text { 72-year-old male, } \\
\text { small boat, no } \\
\text { life jacket, fishing } \\
\text { alone. }\end{array}$ & Wear a life jacket. & $110.7^{*}$ & $\begin{array}{l}\text { Do not engage in } \\
\text { water recreation } \\
\text { alone. }\end{array}$ & 92.9 & $\begin{array}{l}\text { River safety } \\
\text { education including } \\
\text { recognition and } \\
\text { awareness of } \\
\text { hazards. }\end{array}$ & 71.4 & $\begin{array}{l}\text { Learn to swim with } \\
\text { a focus on survival } \\
\text { swimming skills. }\end{array}$ & 50.0 & $\begin{array}{l}\text { Strategies to survive } \\
\text { cold water immersion. }\end{array}$ & 25.0 \\
\hline 4 & $\begin{array}{l}\text { 3-year-old } \\
\text { female, no adult } \\
\text { supervision, fall } \\
\text { into water. }\end{array}$ & $\begin{array}{l}\text { Caregivers } \\
\text { maintaining active } \\
\text { supervision. }\end{array}$ & 107.1 * & $\begin{array}{l}\text { Barriers between } \\
\text { child play areas and } \\
\text { rivers. }\end{array}$ & 75.0 & $\begin{array}{l}\text { River safety } \\
\text { education including } \\
\text { recognition and } \\
\text { awareness of } \\
\text { hazards. }\end{array}$ & 53.6 & Wear a life jacket. & 39.3 & $\begin{array}{l}\text { Learn to swim with } \\
\text { a focus on survival } \\
\text { swimming skills. }\end{array}$ & 32.1 \\
\hline 5 & $\begin{array}{l}\text { Group of } \\
\text { males } 25-54 \\
\text { years, alcohol } \\
\text { consumption, } \\
\text { boating, jumping } \\
\text { in. }\end{array}$ & $\begin{array}{l}\text { Prohibiting/ } \\
\text { Restricting alcohol } \\
\text { use. }\end{array}$ & 96.4 & $\begin{array}{l}\text { Raise awareness } \\
\text { of the risks of } \\
\text { drowning from } \\
\text { alcohol. }\end{array}$ & 85.7 & $\begin{array}{l}\text { River safety } \\
\text { education including } \\
\text { recognition and } \\
\text { awareness of } \\
\text { hazards. }\end{array}$ & 64.3 & $\begin{array}{l}\text { Avoid open water at } \\
\text { night. }\end{array}$ & 53.6 & Wear a life jacket. & 39.3 \\
\hline 6 & $\begin{array}{l}\text { 70-year-old male, } \\
\text { swimming alone, } \\
\text { pre-existing } \\
\text { medical condition. }\end{array}$ & $\begin{array}{l}\text { Do not engage in } \\
\text { water recreation } \\
\text { alone. }\end{array}$ & 92.9 & $\begin{array}{l}\text { River safety } \\
\text { education including } \\
\text { recognition and } \\
\text { awareness of } \\
\text { hazards. }\end{array}$ & 50.0 & $\begin{array}{l}\text { Swim/recreate/ } \\
\text { wash/bathe only } \\
\text { in designated safe } \\
\text { places. }\end{array}$ & 39.3 & $\begin{array}{l}\text { Community- } \\
\text { wide rescue and } \\
\text { resuscitation skills. }\end{array}$ & 32.1 & $\begin{array}{l}\text { Community risk } \\
\text { mapping and } \\
\text { assessment to } \\
\text { formulate targeted } \\
\text { prevention } \\
\text { programmes. }\end{array}$ & 28.6 \\
\hline 7 & $\begin{array}{l}\text { Mid-40s } \\
\text { female, alcohol } \\
\text { intoxication, } \\
\text { slippery river } \\
\text { bank, alone, } \\
\text { night-time. }\end{array}$ & $\begin{array}{l}\text { Raise awareness of } \\
\text { the risks of drowning } \\
\text { from alcohol. }\end{array}$ & 85.7 & $\begin{array}{l}\text { River safety } \\
\text { education including } \\
\text { recognition and } \\
\text { awareness of } \\
\text { hazards. }\end{array}$ & 71.4 & $\begin{array}{l}\text { Designing the } \\
\text { urban landscape to } \\
\text { improve safety. }\end{array}$ & 60.7 & $\begin{array}{l}\text { Community risk } \\
\text { mapping and } \\
\text { assessment to } \\
\text { formulate targeted } \\
\text { prevention } \\
\text { programmes. }\end{array}$ & 46.4 & $\begin{array}{l}\text { Avoid open water at } \\
\text { night. } \\
\text { Build safe and } \\
\text { accessible } \\
\text { infrastructure such as } \\
\text { bridges. }\end{array}$ & $\begin{array}{l}39.3 \\
39.3\end{array}$ \\
\hline 8 & $\begin{array}{l}\text { Group of men and } \\
\text { women 18-30 } \\
\text { years, remote } \\
\text { area, swimming, } \\
\text { weak swimmer, } \\
\text { strong current, } \\
\text { steep drop- } \\
\text { off, unfamiliar } \\
\text { location. }\end{array}$ & $\begin{array}{l}\text { Learn to swim with } \\
\text { a focus on survival } \\
\text { swimming skills. }\end{array}$ & 82.1 & $\begin{array}{l}\text { River safety } \\
\text { education including } \\
\text { recognition and } \\
\text { awareness of } \\
\text { hazards. }\end{array}$ & 78.6 & $\begin{array}{l}\text { Community- } \\
\text { wide rescue and } \\
\text { resuscitation skills. }\end{array}$ & 78.6 & $\begin{array}{l}\text { Swim/recreate/ } \\
\text { wash/bathe only } \\
\text { in designated safe } \\
\text { places. }\end{array}$ & 60.7 & $\begin{array}{l}\text { Signage. } \\
\text { Public rescue } \\
\text { equipment available. }\end{array}$ & $\begin{array}{l}39.3 \\
39.3\end{array}$ \\
\hline 9 & $\begin{array}{l}\text { Group of males } \\
\text { late teens and } \\
\text { early } 20 \text { s, rope } \\
\text { swing, jumping in } \\
\text { from bridge, peer } \\
\text { pressure, hidden } \\
\text { debris. }\end{array}$ & $\begin{array}{l}\text { River safety } \\
\text { education including } \\
\text { recognition and } \\
\text { awareness of } \\
\text { hazards. }\end{array}$ & 92.9 & $\begin{array}{l}\text { Swim/recreate/ } \\
\text { wash/bathe only } \\
\text { in designated safe } \\
\text { places. }\end{array}$ & 71.4 & $\begin{array}{l}\text { Raise awareness } \\
\text { of the risks of } \\
\text { drowning from } \\
\text { alcohol. }\end{array}$ & 67.9 & $\begin{array}{l}\text { Community risk } \\
\text { mapping and } \\
\text { assessment to } \\
\text { formulate targeted } \\
\text { prevention } \\
\text { programmes. }\end{array}$ & 46.4 & Signage. & 39.3 \\
\hline 10 & $\begin{array}{l}\text { Male in } 60 \text { s, } \\
\text { fishing alone, } \\
\text { fall, no life jacket, } \\
\text { bulky clothing, } \\
\text { reduced skill and } \\
\text { fitness due to age. }\end{array}$ & $\begin{array}{l}\text { Do not engage in } \\
\text { water recreation } \\
\text { alone. }\end{array}$ & 85.7 & $\begin{array}{l}\text { River safety } \\
\text { education including } \\
\text { recognition and } \\
\text { awareness of } \\
\text { hazards. }\end{array}$ & 75.0 & Wear a life jacket. & 57.1 & $\begin{array}{l}\text { Strategies to } \\
\text { survive cold water } \\
\text { immersion. }\end{array}$ & 46.4 & $\begin{array}{l}\text { Community risk } \\
\text { mapping and } \\
\text { assessment to } \\
\text { formulate targeted } \\
\text { prevention } \\
\text { programmes. }\end{array}$ & 42.9 \\
\hline
\end{tabular}

The percentage columns relate to the proportion of respondents who identified the strategy as being effective in reducing the kind of river drowning described in the scenario. Strategies marked with an * amount to more than $100 \%$ when strategies listed under the 'other' section were thematically recoded. Strategies which appear more than once are shaded in darker colour and those that appear only once in the top 3 are shaded in lighter colour. 
Table 5 Final list of the most effective river drowning prevention strategies, country context, levels of evidence and level on the hierarchy of control $(n=13)$

\begin{tabular}{|c|c|c|c|c|}
\hline Strategy & Average score $(\%)$ & $\begin{array}{l}\text { Effective in both } \\
\text { HICs and LMICs (\%) }\end{array}$ & $\begin{array}{l}\% \text { Aware of evidence } \\
\text { supporting strategy }\end{array}$ & Hierarchy of control level \\
\hline Barriers between child play areas and rivers & 75.0 & 71.4 & 71.4 & Engineering \\
\hline River safety education including recognition and awareness of hazards & 69.7 & 92.9 & 32.1 & Education \\
\hline Raise awareness of the risks of drowning from alcohol & 61.9 & 67.9 & 50.0 & Low-order \\
\hline Prohibiting/Restricting alcohol use & 53.6 & 50.0 & 32.1 & Elimination \\
\hline Close flooded roads and/or use physical barriers (such as booms) & 50.0 & 57.1 & 57.1 & Engineering/Elimination \\
\hline Swim/recreate/wash/bathe only in designated safe places & 40.6 & 75.0 & 39.3 & Low-order \\
\hline Build safe and accessible infrastructure such as bridges & 40.5 & 78.6 & 50.0 & Engineering \\
\hline Do not engage in water recreation alone & 38.8 & 82.1 & 32.1 & Elimination/Administrative \\
\hline Wear a life jacket & 38.8 & 57.1 & 82.1 & PPE \\
\hline Learn to swim with a focus on survival swimming skills & 35.3 & 85.7 & 78.6 & Low-order \\
\hline Community-wide rescue and resuscitation skills & 24.6 & 82.1 & 32.1 & Low-order \\
\hline Caregivers maintaining active supervision & 22.0 & 82.1 & 82.1 & Administrative \\
\hline Designing the urban landscape to improve safety & 19.2 & 60.7 & 39.3 & Engineering \\
\hline
\end{tabular}

HICS, high-income countries; LMICs, low-income and middle-income countries; PPE, personal protective equipment.

medical assistance, and only 33\% of river users had a current cardiopulmonary resuscitation (CPR) qualification. ${ }^{42}$ Training bystanders in safe rescue and resuscitation is also recommended by the WHO as a strategy to mitigate the impact of drowning. ${ }^{4}$ While bystanders who undertake aquatic rescues and perform CPR help to save lives, in particular at unpatrolled locations, this is not without risk to the rescuer, ${ }^{43}$ and self-preservation must be key.

\section{Signage}

In Australia, signage is commonly recommended as a strategy for improving safety at rivers, often as a form of remote supervision. ${ }^{44}$ Signage was also found to be a common theme in coronial recommendations associated with river drowning fatalities in Australia. ${ }^{30}$ While signage may be a more feasible alternative to lifeguards, it needs to be part of a comprehensive drowning prevention strategy, noting there is limited evidence supporting its effectiveness when used in isolation ${ }^{21}$ and no research specific to a river context. ${ }^{45} 46$ The two studies conducted to date examining the effectiveness of signage were both conducted in the beach context, ${ }^{45}$ and found that international students rarely used beach signage reports and a third would not swim between the flags, ${ }^{45}$ while a survey of beach users in the Australian state of Victoria found that just $45 \%$ of respondents reported observing any signage at the beach. Further, composition of the sign nor symbol shape affected recognition. ${ }^{46}$ Although 24 strategies that involved signage were mentioned at phase 1 , due to a lack of support, signage did not feature in the final list, indicating a need for further evidence to support its effectiveness and therefore use.

\section{Country context}

This study considered the likely effectiveness of proposed river drowning prevention strategies in both HICs and LMICs. Critical assessment of the appropriateness of river drowning prevention scenarios for LMICs must be conducted. Underlying determinants of health, ${ }^{11}$ such as socioeconomic status, education level and physical environment, are factors which impact the risk of drowning and need to be considered when developing prevention strategies. Resource implication needs to be considered in light of effectiveness; for example, provision of life jackets is a high-cost strategy low on the order of the hierarchy of control (PPE), whereas signage is a lower cost strategy but higher on the hierarchy of control (administrative controls); however, effectiveness of signage is unclear. Developing higher order control strategies such as providing a safe place for preschool children away from the water (ie, community crèches) are likely to be more effective in reducing drowning and also more cost-effective in LMIC countries. ${ }^{47}$

Similarly, strategies such as learning to swim rely on identifying a skill base and expertise within the country, as well as safe swimming space being available, in order to be successful and sustainable. ${ }^{47}$ Critical reflection is needed to determine the environment to be used for teaching swimming, for example, the transfer of skills learnt in a still water environment to open water environments such as rivers. Engineering solutions are also likely to be costly, both the initial installation as well as ongoing maintenance. Further research is required to identify the barriers to implementing river drowning prevention strategies in both HICs and LMICs in order to implement measures to address these barriers.

\section{Further research}

Further research includes the need to implement and evaluate the proposed strategies (including local adjustments); increased understanding of the epidemiology of river drowning in other countries, especially LMICs; evaluation of the best method to provide schoolbased river safety education; type of messaging, placement and design for safety signage at river locations (including evaluating their impact); and factors impacting lifejacket wear.

\section{Limitations}

There are limitations associated with this study. This study represents the opinions of those who agreed to participate in the study only. The strategies recommended were influenced by the scenarios used, which although likely to be similar internationally only depict drowning scenarios from Australia. Different scenarios may result in different strategies being recommended. Respondents did not have to provide the specific pieces of evidence they based their assessment on. While it would be reasonable to believe that the $65.5 \%$ of participants who are researchers or researchers and practitioners would be aware of the evidence on river drowning prevention strategies, the $34.5 \%$ of Delphi participants who are practitioners may be less likely to be aware of such evidence. There may be limitations associated 
with having HIC participants comment on the effectiveness of river drowning prevention strategies in LMICs and vice versa.

\section{CONCLUSION}

It is critical that river drowning prevention is prioritised given its burden. In the absence of evidence, a Delphi process can be used to identify strategies that are more likely to be effective. This study represents a vital first step in identifying and prioritising river drowning prevention strategies, especially those targeted at alcohol consumption, learning to swim, flood management and the wear/use of life jackets. Future research is required to assess the efficacy of the 13 interventions recommended by this study (including implementation and evaluation). Such work is required in both HIC and LMIC contexts to further enhance efforts to save lives from drowning in rivers.

\section{What is already known on the subject}

- Rivers are a leading location for drowning globally and the leading location for drowning in Australia.

- A systematic review of literature identified few implemented and evaluated drowning prevention strategies for rivers.

- Epidemiological analysis of river drowning in Australia has identified males, alcohol consumption, flooding and geographical remoteness as risk factors.

\section{What this study adds}

- Thirteen possible strategies for preventing river drowning deaths were identified, targeting areas including alcohol consumption, flooding, child supervision, learning to swim, wear/use of life jackets and community-wide resuscitation skills.

- All 13 strategies were deemed as likely to be effective and capable of being applied, in both high-income countries (HICS) and low-income and middle-income countries (LMICS).

- A Delphi process is a useful starting point for identifying river drowning prevention strategies; efficacy of findings must now be validated through implementation and evaluation in both HICs and LMICs.

Acknowledgements The authors would like to acknowledge and thank the following participants who kindly volunteered their time to be a part of this project: Dr Shayne Baker, Dr Steve Beerman, Dr Elizabeth Bennett, Dr Joost Bierens, Dr Lyndal Bugeja, Dr Tessa Clemens, John Connolly, Mike Dunn, Professor Gerry Fitzgerald, Dr Julie Gilchrist, Andrew Gissing, Dan Graham, Jonathan Gueverra, Professor Sebastian Jonkman, Dr Olive Kobusingye, Dr Mike Linnan, Scott Liske, Michael Martino, Tom Mecrow, Dr David Meddings, Jonathan Passmore, Dr Linda Quan, Dr Aminur Rahman, Dr Colleen Saunders, Dr Becky Sindall, Dr David Szpilman, Evan Walter, Aaron Wright.

Contributors AEP and RCF conceptualised the study. AEP and RCF identified the experts, and AEP invited them to participate. AEP and RCF designed the surveys. AEP collated the data and conducted the analysis. RCF provided assistance and advice on data analysis. AEP drafted the manuscript. RCF reviewed and revised the manuscript. $P A L$ reviewed and revised the manuscript.

Funding This research is supported by the Royal Life Saving Society - Australia to aid in the reduction of drowning. Research at the Royal Life Saving Society Australia is supported by the Australian Government. Lead author AEP's doctoral studies are supported through an Australian Government Research Training Program Scholarship.

Competing interests None declared.

Patient consent for publication Not required.
Ethics approval Ethical approval was granted by James Cook University Human Research Ethics Committee (HREC) (H7166).

Provenance and peer review Not commissioned; externally peer reviewed.

Open access This is an open access article distributed in accordance with the Creative Commons Attribution Non Commercial (CC BY-NC 4.0) license, which permits others to distribute, remix, adapt, build upon this work non-commercially, and license their derivative works on different terms, provided the original work is properly cited, appropriate credit is given, any changes made indicated, and the use is non-commercial. See: http://creativecommons.org/licenses/by-nc/4.0/.

\section{ORCID iDs}

Amy E Peden http://orcid.org/0000-0002-6424-1511

Richard C Franklin http://orcid.org/0000-0003-1864-4552

\section{REFERENCES}

1. Pearn JH, Nixon JW, Franklin RC, et al. Safety legislation, public health policy and drowning prevention. Int J Inj Contr Saf Promot 2008;15:122-3.

2. Bugeja L, Franklin RC. An analysis of stratagems to reduce drowning deaths of young children in private swimming pools and Spas in Victoria, Australia. Int J Inj Cont Saf Promot 2012:1-13.

3. Krug EG, Sharma GK, Lozano R. The global burden of injuries. Am J Public Health 2000;90:523-6.

4. World Health Organization. Preventing drowning: an implementation guide. World Health Organization, 2017

5 Peden AE, Franklin RC, Mahony AJ, et al. Using a retrospective cross-sectional study to analyse unintentional fatal drowning in Australia: ICD-10 coding-based methodologies verses actual deaths. BMJ Open 2017;7.

6. Dietz PE, Baker SP. Drowning: epidemiology and prevention. Am J Public Health 1974;64:303-12

7. Patetta MJ, Biddinger PW. Characteristics of drowning deaths in North Carolina. Public Health Rep 1988;103:406-11.

8. Lunetta P, Smith GS, Penttilä A, et al. Unintentional drowning in Finland 1970-2000: a population-based study. Int J Epidemiol 2004;33:1053-63.

9. Kiakalayeh AD, Mohammadi R, Ekman DS, et al. Unintentional drowning in northern Iran: a population-based study. Accid Anal Prev 2008;40:1977-81.

10. Rahman A, Mashreky SR, Chowdhury SM, et al. Analysis of the childhood fatal drowning situation in Bangladesh: exploring prevention measures for low-income countries. Inj Prev 2009;15:75-9.

11. McKeown T. Determinants of health. Human Nature 1978:1:57-62

12. Peden $A E$, Franklin $R C$, Leggat $P A$. The hidden tragedy of rivers: a decade of unintentional fatal drowning in Australia. PLoS One 2016;11:e0160709.

13. Peden $A E$, Franklin $R C$, Leggat PA. Alcohol and its contributory role in fatal drowning in Australian rivers, 2002-2012. Accid Anal Prev 2017:98:259-65.

14 Peden AE, Franklin RC, Leggat PA, et al. Causal pathways of flood related river drowning deaths in Australia. PLoS Currents Disasters 2017; May 18

15. World Health Organization. Ottawa charter for health promotion. First International Conference on health promotion. Ottawa, 1986.

16. SvanstrÖM L, Schelp L, SkjÖNberg G. The establishment of a national safety promotion programme for prevention of accidents and injuries - the first Swedish 'Health For All'_programme implemented in practice. Health Promot Int 1989:4:343-7

17. Luau HC, Svanström L, Ekman R, et al. Development of a national injury prevention/ safe community programme in Vietnam. Health Promot Int 2001;16:47-54.

18. Szpilman D, Tipton M, Sempsrott J, et al. Drowning timeline: a new systematic model of the drowning process. Am J Emerg Med 2016;34:2224-6.

19. Haddon JW. On the escape of tigers an ecologic note - strategy options in reducing losses in energy damaged people and property. Am J Public Health Nations Health 1970;60:2229-34.

20. Franklin RC, Scarr J. A Framework for Prevention. In: Bierens J, ed. Drowning. Berlin Heidelberg, Springer-Verlag, 2014: 153-63.

21. Peden $A E$, Franklin $R C$, Leggat $P A$. Fatal river drowning: the identification of research gaps through a systematic literature review. Inj Prev 2016;22:202-9.

22. Gupta UG, Clarke RE. Theory and applications of the Delphi technique: a bibliography (1975-1994). Technol Forecast Soc Change 1996;53:185-211.

23. Sackman H. Delphi assessment: expert opinion, forecasting, and group process. Santa Monica, California: RAND, 1974.

24. Quan L, Bennett E, Moran K, et al. Use of a consensus-based process to develop international guidelines to decrease recreational open water drowning deaths. Int J Health Promot Educ 2012;50:135-44.

25. Moran K, Quan L, Franklin R, et al. Where the evidence and expert opinion meet: a review of Open-Water recreational safety messages. Int J Aquatic Res Educ 2011:5:251-70

26. Gizmo S, Gizmo S, 2018. Available: www.surveygizmo.com [Accessed 19 Feb 2018]

27. Streeton R, Cooke M, Campbell J. Researching the researchers: using a snowballing technique. Nurse Res 2004:12:35-46.

28. Braun V, Clarke V. Using thematic analysis in Psychology. Qual Res Psychol 2006;3:77-101. 
29. World Health Organization. Global report on drowning: preventing a leading killer. Geneva: World Health Organization, 2014.

30 Peden AE, Franklin RC, Leggat PA. Preventing river drowning deaths: lessons from coronial recommendations. Health Promot J Austr 2018;29:144-52.

31. O'Connor PJ, O'Connor N, O'Connor P. Causes and prevention of boating fatalities. Accid Anal Prev 2005;37:689-98.

32. Hudson D, Ekman R, Svanström L. Survival of immersions during recreational boating events in Alaska, 1999-2004. Accid Anal Prev 2007:39:437-43.

33. Wintemute GJ, Anton A, Andrada E, et al. Compliance with an ordinance requiring the use of personal flotation devices by children in public waterways. West J Emerg Med 2013;14:200-3.

34. Milio N. Making healthy public policy; developing the science by learning the art: an ecological framework for policy studies. Health Promot Int 1987;2:263-74.

35 Peden AE, Demant D, Hagger MS, et al. Personal, social, and environmental factors associated with lifejacket wear in adults and children: a systematic literature review. PLoS One 2018;13:e0196421.

36. Szpilman D, Webber J, Quan L, et al. Creating a drowning chain of survival. Resuscitation 2014;85:1149-52.

37. Cohen L, Swift S. The spectrum of prevention: developing a comprehensive approach to injury prevention. Inj Prev 1999;5:203-7.

38. Duperrex O, Bunn F, Roberts I. Safety education of pedestrians for injury prevention: a systematic review of randomised controlled trials. BMJ 2002;324:1129.
39. Yang L, Nong Q-Q, Li C-L, et al. Risk factors for childhood drowning in rural regions of a developing country: a case-control study. Inj Prev 2007;13:178-82.

40. Wallis $B A$, Watt $K$, Franklin RC, et al. Interventions associated with drowning prevention in children and adolescents: systematic literature review. Inj Prev 2015;21:195-204.

41. Widome MD. Remembering as we look ahead: the three E's and firearm injuries. Pediatrics 1991:88:379-83.

42. Peden AE, Franklin RC, Leggat PA. Cardiopulmonary resuscitation and first-aid training of river users in Australia: a strategy for reducing drowning. Health Promot J Austr 2018;115.

43. Franklin RC, Pearn JH. Drowning for love: The aquatic victim-instead-of-rescuer syndrome: drowning fatalities involving those attempting to rescue a child. J Paediatr Child Health 2011;47:44-7.

44. Statewide Mutual. Signs as remote supervision: best practice manual. version 3, 2007

45. Ballantyne R, Carr N, Hughes K. Between the flags: an assessment of domestic and international university students' knowledge of beach safety in Australia. Tour Manag 2005;26:617-22.

46. Matthews B, Andronaco R, Adams A. Warning signs at beaches: do they work? Saf Sci 2014:62:312-8.

47. Rahman F, Bose $S$, Linnan $M$, et al. Cost-effectiveness of An injury and drowning prevention program in Bangladesh. Pediatrics 2012;130:e1621-8. 